\title{
ERRATUM
}

Johannes C. M. Scholten · J. Colin Murrell

Donovan P. Kelly

\section{Growth of sulfate-reducing bacteria and methanogenic archaea with methylated sulfur compounds: a commentary on the thermodynamic aspect}

Published online: 1 February 2003

(C) Springer-Verlag 2003

\section{Arch Microbiol (2003) DOI 10.1007/s00203-002-0509-0}

An incorrect version of Table 7 was printed. The correct version is supplied below.

Table 7 The calculated $\gamma_{\mathrm{d}}, D_{\mathrm{s}}{ }^{01} / R_{\mathrm{Ax}}$ and $Y_{\mathrm{DX}}$ for reactions involved in the sulfidogenic and methanogenic degradation of various methylated sulfur compounds

\begin{tabular}{lclll}
\hline S-compound & Reaction & $\begin{array}{l}\gamma_{\mathrm{d}}^{\mathrm{a}} \\
\text { degree of } \\
\text { reduction }\end{array}$ & $\begin{array}{l}D_{\mathrm{s}}^{01} / R_{\mathrm{Ax}}{ }^{\mathrm{b}} \\
\mathrm{kJ} / \mathrm{C} \text {-mol } \\
\text { biomass }\end{array}$ & $\begin{array}{l}Y_{\mathrm{Dx}}^{\mathrm{c}} \\
\left(\mathrm{C}-\mathrm{mol}_{\mathrm{biomas}}\right. \\
\mathrm{C}-\mathrm{mol} \mathrm{S}_{\mathrm{x}}\end{array}$ \\
\hline Dimethylsulfide & 1 & 7 & 1011 & 0.045 \\
Dimethylsulfoniopropionate & 4 & 7 & 1011 & 0.027 \\
3-S-methylmercaptopropionate & 5 & 7 & 1011 & 0.011 \\
Methanethiol & 7 & 7 & 1011 & 0.055 \\
Dimethylsulfide & 8 & 7 & 1011 & 0.035 \\
3-S-methylmercaptopropionate & 12 & 7 & 1011 & 0.008 \\
Methanethiol & 15 & 7 & 1011 & 0.033 \\
\hline
\end{tabular}

aDegree of reduction of electron donor was calculated according to J.J. Heijnen (personal communication, 2002, Delft University of Technology, The Netherlands)

${ }^{\mathrm{b}} \mathrm{Ds}^{01} / R_{\mathrm{Ax}}$ was calculated according to Heijnen and Van Dijken (1992)

${ }^{\mathrm{c}} \mathrm{Y}_{\mathrm{DX}}$ was calculated from $D_{\mathrm{s}}^{01} / R_{\mathrm{Ax}}^{\mathrm{b}}$ 